\title{
Trends and risk factors of mortality analysis in patients with inflammatory bowel disease: a Taiwanese nationwide population-based study
}

Wei-Chen Lin 1,2,3, Meng-Tzu Weng 4,5, Chien-Chih Tung ${ }^{4}$, Yuan-Ting Chang ${ }^{6}$, Yew-Loong Leong ${ }^{7}$, Yu-Ting Wang ${ }^{8}$, Horng-Yuan Wang ${ }^{1,2,3}$, Jau-Min Wong ${ }^{4}$ and Shu-Chen Wei ${ }^{4,8^{*}}$ (⿺辶)

\begin{abstract}
Background: Inflammatory bowel disease (IBD) was emerging as a worldwide epidemic disease, and the advanced therapy changed the clinical course and possibly the outcomes. Our previous study reported a higher mortality rate from (IBD) in Taiwan than in Western countries. We proposed to analyze the trend and risk factors of mortality in order to improve the care quality of IBD patients.

Methods: This retrospective study was conducted to analyze data for January 2001 to December 2015 from a registered database, compiled by the Taiwan's National Health Insurance.

Results: Between 2001 and 2015, a total of 3806 IBD patients [Crohn's disease (CD): 919; ulcerative colitis (UC): 2887] were registered as having catastrophic illness, and $8.2 \%$ of these patients died during follow-up. The standardized mortality ratios (SMRs) of CD and UC were 3.72 (95\% Cl 3.02-4.55) and 1.44 (95\% Cl 1.26-1.65), respectively, from 2001 to 2015, respectively. A comparison of the periods of 2011-2015 and 2001-2005 revealed a decrease in the mortality rates from both UC and CD. Multivariate Cox proportional hazards analysis identified elderly individuals; sepsis and pneumonia were the risk factors for IBD mortality. The specific risk factors of mortality were liver cancer for UC and surgeries for CD.
\end{abstract}

Conclusion: For further decreasing IBD-related mortality in Taiwan, we need to pay special attention toward elderly individuals, infection control, cancer screening and improvement in perioperative care.

Keywords: Crohn's disease, Inflammatory bowel disease, Mortality, Risk factors, Ulcerative colitis

\section{Introduction}

Inflammatory bowel diseases (IBDs), which comprise ulcerative colitis (UC) and Crohn's disease (CD), are chronic gastrointestinal disorders causing severe complications, such as toxic megacolon, sepsis, and thromboembolism [1]. Mortality from UC was sixfold higher than that from CD in 1951, and these rates have followed a parallel time course since 1975 [2]. Even with

\footnotetext{
*Correspondence: shuchenwei@ntu.edu.tw

${ }^{4}$ Department of Internal Medicine, National Taiwan University Hospital and College of Medicine, Taipei City, Taiwan

Full list of author information is available at the end of the article
}

advancements in medical and surgical interventions, the mortality rates of IBD are still higher than what was previously understood [3]. A meta-analysis reported that the mortality rate from UC decreased and the survival rate was almost equal to that of the general population [4], whereas the mortality rate from $\mathrm{CD}$ remained high [5].

IBD can result in direct or indirect mortality. One-fifth of IBD-related are directly related to UC, which is less than a third of deaths caused by CD [6]. Mortality rates may vary geographically; for example, mortality rates are lower in Europe and North America because of the better healthcare system [6]. IBD mortality data from the Asia Pacific region are scant. Our previous study indicated a

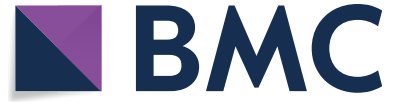

c) The Author(s) 2019. This article is licensed under a Creative Commons Attribution 4.0 International License, which permits use, sharing, adaptation, distribution and reproduction in any medium or format, as long as you give appropriate credit to the original author(s) and the source, provide a link to the Creative Commons licence, and indicate if changes were made. The images or other third party material in this article are included in the article's Creative Commons licence, unless indicated otherwise in a credit line to the material. If material is not included in the article's Creative Commons licence and your intended use is not permitted by statutory regulation or exceeds the permitted use, you will need to obtain permission directly from the copyright holder. To view a copy of this licence, visit http://creativeco mmons.org/licenses/by/4.0/. The Creative Commons Public Domain Dedication waiver (http://creativecommons.org/publicdomain/ zero/1.0/) applies to the data made available in this article, unless otherwise stated in a credit line to the data. 
higher IBD mortality rate in Taiwan than in other Asian and Western countries, especially due to CD, from 1998 to 2008 [7]. For addressing this significant increase in the incidence and prevalence of IBD [7], we organized the IBD patient association to enhance patient knowledge of IBD symptoms, potential benefits and side effects of treatment since 2009. For physicians, we developed a series of comprehensive, practical education programs and on-line resources to improve the experience of gastroenterologists with management of IBD since 2010.

The primary aim of this study was to examine whether there has been a change in IBD mortality rate in Taiwan following the promotion of IBD-related educational programs since 2009. The secondary aim of the study was to analyze the risk factors of IBD deaths, which will help improve the quality of care for IBD patients.

\section{Methods}

\section{Data source}

Data were obtained from the Health and Welfare Data Science Center, Ministry of Health and Welfare (HWDC, MOHW). Established in 1995, the National Health Insurance (NHI) system in Taiwan is compulsory for all its residents and covers over $99 \%$ of the total population of approximately 23 million people. Since 1997, CD and UC are registered as catastrophic illnesses because of their potential for repetitive admissions and the need for chronic, careful care. Healthcare providers need to provide the patient's clinical history record, endoscopic reports, image and histologic results when applying for the registration. NHI reviewers approve or decline the registration after reviewing the application. Therefore, not all clinical patients with IBD are registered, although most registered patients have confirmed IBD.

This nationwide population-based Taiwanese study of IBD was compiled between January 2001 and December 2015. NHI claims data provide clinical information including prescription, diagnoses, and hospitalizations for population-based epidemiologic research [8]. Under strict confidentiality guidelines and in accordance with personal electronic data protection regulations, the data of the study population were obtained from the HWDC, MOHW data (including Catastrophic Illness Registry and Taiwan Cancer Registry), Department of Statistics of the MOHW, Taiwan. This study was approved by the Institutional Review Board of the National Taiwan University Hospital (IRB Number 201507018 W). No informed consent is required under the Taiwan regulations for registry-based studies involving no contact with the study subjects.

\section{Patient identification}

We used the diagnostic code [The International Classification of Diseases (ICD), Ninth and Tenth Revision, Clinical Modification] to retrieve data of the IBD patients (ICD-9 codes of 555 for CD and 556 for UC, other associated ICD codes are mentioned in Table 1) from the Catastrophic Illness Registry. For each patient, medical records were collected in the NHI claims database, including clinical diagnosis, as well as outpatient and hospitalization records. Age at IBD registration was defined as when patients were registered owing to catastrophic illnesses based on clinical, endoscopic, radiological, and histological features. Five most frequent comorbidities associated with mortality in Taiwan [hypertension, diabetes mellitus, hyperlipidemia, chronic obstructive pulmonary disease (COPD), and hepatitis] were included in the analysis. Extraintestinal manifestations (EIMs), namely uveitis, erythema nodosum, psoriasis, arthritis, cholangitis, deep venous thrombosis, and pulmonary embolism, were included in the analysis. We defined IBD complications as presence of fistula or abdominal abscess.

\section{Statistical analyses}

We described the characteristics of IBD patients, including the year of IBD registered, sex ratio, and age distribution, in this study. Mortality was compared with that in the survival group by using the independent $t$ test and Chi square test. The Cox proportional hazards model was applied to analyze the effect of multiple covariates in predicting mortality in patients with IBD. The adjusted hazard ratio was dependent on each factor of the significant univariate factors in UC and CD patients. The survival of IBD patients was assessed using the Kaplan-Meier life-table method, and the differences were evaluated using the log rank test. To evaluate the trends of mortality rate and the effect of age on mortality, the study was divided into 3 consecutive periods of 5 years (2001-2005, 2006-2010, and 2011-2015) and 3 age groups ( $\leq 39$, $40-59, \geq 60$ years). The mortality rate was defined as the number of IBD deaths per 1000 persons per year. Specific mortality rates were calculated as the death rates of the specific group among patients. Standardized mortality ratios (SMRs) were estimated as the observed number of deaths divided by the expected number of deaths, and $95 \%$ confidence intervals (CIs) were calculated using Poisson distribution. The standard population was the national population, and the number of expected deaths was calculated on the basis of the number of deaths and number of people in the middle of the year in Taiwan. All statistical analyses were performed using SAS version 9.4 (SAS Institute, Cary, NC, USA). A p value of $<0.05$ was considered statistically significant. 
Table 1 Characteristics of IBD patients registered in the Catastrophic Illness Registry, Taiwan, 2001-2015

\begin{tabular}{|c|c|c|c|c|}
\hline & ICD-9 and 10 & $\begin{array}{l}\text { Crohn's disease } \\
N(\%)\end{array}$ & $\begin{array}{l}\text { Ulcerative colitis } \\
N(\%)\end{array}$ & p value \\
\hline Total & & $919(100.0)$ & $2887(100.0)$ & \\
\hline Gender & & & & $<0.001$ \\
\hline Male & & $631(68.7)$ & $1787(61.9)$ & \\
\hline Female & & $288(31.3)$ & $1100(38.1)$ & \\
\hline IBD registered age & & & & $<0.001$ \\
\hline$\leq 39$ & & $543(59.1)$ & $1118(38.7)$ & \\
\hline $40-59$ & & $241(26.2)$ & $1251(43.3)$ & \\
\hline$\geq 60$ & & $135(14.7)$ & $518(17.9)$ & \\
\hline \multicolumn{5}{|l|}{ Operation } \\
\hline Colectomy & 73014B & $6(0.6)$ & $9(0.3)$ & 0.221 \\
\hline Colostomy & $73022 B$ & $73(7.9)$ & $122(4.2)$ & $<0.001$ \\
\hline Exploratory laparotomy & $75805 B$ & $25(2.7)$ & $13(0.5)$ & $<0.001$ \\
\hline Ileostomy & 73,015-7B & $27(2.9)$ & $78(2.7)$ & 0.703 \\
\hline \multicolumn{5}{|l|}{ Comorbidity } \\
\hline Hypertension & $401 ; A 260,269 ; 110$ & $166(18.1)$ & $674(23.3)$ & 0.001 \\
\hline Diabetes & 250; A181;E101-19,131 & $87(9.5)$ & $326(11.3)$ & 0.121 \\
\hline Hyperlipidemia & 272, A189;E752,77-8,88 & $121(13.2)$ & $599(20.7)$ & $<0.001$ \\
\hline COPD & 491-2; A323;J41-4 & $58(6.3)$ & $229(7.9)$ & 0.105 \\
\hline Hepatitis & 70; A46; B15-9 & $62(6.7)$ & $251(8.7)$ & 0.061 \\
\hline \multicolumn{5}{|l|}{ EIM } \\
\hline Uveitis & 360; A239; H440-9 & $23(2.5)$ & $90(3.1)$ & 0.339 \\
\hline Psoriasis & 696; A429; L305,40-8 & $56(6.1)$ & $136(4.7)$ & 0.095 \\
\hline Erythema nodosum & 695.2; A429; L52 & $25(2.7)$ & $22(0.8)$ & $<0.001$ \\
\hline Arthritis & 714; A430; M500-840,1200 & $84(9.1)$ & $193(6.7)$ & 0.013 \\
\hline Cholangitis & $576.1 ; \mathrm{K} 830$ & $15(1.6)$ & $27(0.9)$ & 0.078 \\
\hline Deep vein thrombosis & $453,451.1$, A303, 1820-9 & $16(1.7)$ & $32(1.1)$ & 0.135 \\
\hline Pulmonary embolism & 415.1; T800; 12690-9 & $3(0.3)$ & $6(0.2)$ & 0.519 \\
\hline \multicolumn{5}{|l|}{ Complication } \\
\hline Fistula & $569.8,596.1,565$, K602-5 632, & $258(28.1)$ & $381(13.2)$ & $<0.001$ \\
\hline Abdominal wall abscess & $566 ; 569.5 ; \mathrm{K} 610-3630$ & $121(13.2)$ & $107(3.7)$ & $<0.001$ \\
\hline \multicolumn{5}{|l|}{ Cancer } \\
\hline Small intestine cancer & 152 & $0(0.0)$ & $0(0.0)$ & $\mathrm{b}$ \\
\hline Colorectal cancer & $153 ; 154$ & $8(0.8)$ & $21(0.7)$ & 0.664 \\
\hline Liver cancer & 155 & $16^{\mathrm{a}}$ & & 0.275 \\
\hline Lymphoma & $200 ; 202$ & $4(0.4)$ & $11(0.4)$ & 0.767 \\
\hline Melanoma & 172.9 & $0(0.0)$ & $0(0.0)$ & b \\
\hline \multicolumn{5}{|l|}{ Hospitalization } \\
\hline Pneumonia & 482-6; A321, 481;J14-8 & $92(10.0)$ & $210(7.3)$ & 0.008 \\
\hline Urinary tract infection & 599; A359; N390 & $111(12.1)$ & $243(8.4)$ & $<0.001$ \\
\hline Sepsis & 038; A038, 409-19 & $169(18.4)$ & $293(10.2)$ & $<0.001$ \\
\hline Survival state & & & & 0.003 \\
\hline Survival & & $823(89.5)$ & $2673(92.6)$ & \\
\hline Mortality & & $96(10.5)$ & $214(7.4)$ & \\
\hline
\end{tabular}

a One group was less than 3 patients and it was not allowed to mention it in detail by the regulations of the Health and Welfare Data Science Center, ${ }^{\text {b }}$ data not applicable 


\section{Results}

\section{Clinical characteristics}

Between 2001 and 2015, a total of 3806 newly diagnosed IBD patients were registered, and their demographic data are summarized in Table 1. Of the total patients, 919 were diagnosed as having CD and 2887 as having UC. The patients were predominantly men, with CD being significantly more prevalent than UC $(\mathrm{p}<0.001)$. The male-tofemale ratio for $\mathrm{CD}$ and $\mathrm{UC}$ was 2.2 and 1.6, respectively (Table 1). The age at disease onset or registration was higher in UC patients than in CD patients $(\mathrm{p}<0.001)$. The incidence rate of $C D$ and $U C$ peaked at the ages of $\leq 39$ and 40-59 years, respectively (Table 1 ).
UC patients had more comorbidities (hypertension and hyperlipidemia) than CD patients. Erythema nodosum and arthritis were the more common EIMs in CD patients. No significant difference was observed with respect to malignancy between the $\mathrm{UC}$ and $\mathrm{CD}$ groups. Colostomy and explorative laparotomy as surgeries; fistula and abdominal wall abscess as complications; and infection (pneumonia, urinary tract infection, and sepsis)-related hospitalizations occurred more frequently in the CD group (Table 1), resulting in CD patients having a higher mortality rate than UC patients $(10.5 \%$ vs. $7.4 \% ; \mathrm{p}=0.003)$.

Table 2 Risk factors of mortality for IBD patients registered in the Catastrophic Illness Registry, Taiwan, 2001-2015

\begin{tabular}{|c|c|c|c|c|c|c|}
\hline & \multicolumn{3}{|l|}{$\mathrm{UC}(n=2887)$} & \multicolumn{3}{|l|}{$\mathrm{CD}(n=919)$} \\
\hline & $\begin{array}{l}\text { Mortality }(n=214) \\
n(\%)\end{array}$ & $\begin{array}{l}\text { Survival }(n=2673) \\
n(\%)\end{array}$ & $p$ value & $\begin{array}{l}\text { Mortality }(n=96) \\
\text { n (\%) }\end{array}$ & $\begin{array}{l}\text { Survival }(n=823) \\
n(\%)\end{array}$ & $p$ value \\
\hline Male sex & $143(66.8)$ & $1644(61.5)$ & & $57(59.4)$ & $574(69.7)$ & 0.038 \\
\hline $\mathrm{IBD}$ registered age & & & $<0.001$ & & & $<0.001$ \\
\hline$\leq 39$ & $24(11.2)$ & $1094(40.9)$ & & $20(20.8)$ & $523(63.6)$ & \\
\hline $40-59$ & $58(27.1)$ & $1193(44.6)$ & & $26(27.1)$ & $215(26.1)$ & \\
\hline$\geq 60$ & $132(61.7)$ & $386(14.4)$ & & $50(52.1)$ & $85(10.3)$ & \\
\hline \multicolumn{7}{|l|}{ Operation } \\
\hline Colectomy & $1(0.5)$ & $8(0.3)$ & 0.501 & $1(1.0)$ & $5(0.6)$ & 0.485 \\
\hline Colostomy & $31(14.5)$ & $91(3.4)$ & $<0.001$ & $21(21.9)$ & $52(6.3)$ & $<0.001$ \\
\hline Exploratory laparotomy & $4(1.9)$ & $9(0.3)$ & 0.012 & $9(9.4)$ & $16(1.9)$ & $<0.001$ \\
\hline Ileostomy & $17(7.9)$ & $61(2.3)$ & $<0.001$ & $8(8.3)$ & $19(2.3)$ & 0.004 \\
\hline \multicolumn{7}{|l|}{ Comorbidity } \\
\hline Hypertension & $94(43.9)$ & $580(21.7)$ & $<0.001$ & $37(38.5)$ & $129(15.7)$ & $<0.001$ \\
\hline Diabetes & $48(22.4)$ & $278(10.4)$ & $<0.001$ & $19(19.8)$ & $68(8.3)$ & $<0.001$ \\
\hline Hyperlipidemia & $42(19.6)$ & $557(20.8)$ & 0.674 & $20(20.8)$ & $101(12.3)$ & 0.019 \\
\hline COPD & $41(19.2)$ & $188(7.0)$ & $<0.001$ & $10(10.4)$ & $48(5.8)$ & 0.081 \\
\hline Hepatitis & $19(8.9)$ & $232(8.7)$ & 0.921 & $7(7.3)$ & $55(6.7)$ & 0.829 \\
\hline \multicolumn{7}{|l|}{ EIM } \\
\hline Uveitis & $0(0.0)$ & $90(3.4)$ & 0.006 & $0(0.0)$ & $23(2.8)$ & 0.159 \\
\hline Psoriasis & $10(4.7)$ & $126(4.7)$ & 0.978 & $2(2.1)$ & $54(6.6)$ & 0.111 \\
\hline Erythema nodosum & $2(0.9)$ & $20(0.8)$ & 0.763 & $1(1.0)$ & $24(2.9)$ & 0.504 \\
\hline Arthritis & $21(9.8)$ & $172(6.4)$ & 0.057 & $7(7.3)$ & $77(9.4)$ & 0.507 \\
\hline Cholangitis & $7(3.3)$ & $20(0.8)$ & 0.003 & $4(4.2)$ & $11(1.3)$ & 0.062 \\
\hline Deep vein thrombosis & $5(2.3)$ & $27(1.0)$ & 0.083 & $5(5.2)$ & $11(1.3)$ & 0.019 \\
\hline \multicolumn{7}{|l|}{ Complication } \\
\hline Fistula & $26(12.2)$ & $355(13.3)$ & 0.638 & $13(13.5)$ & $245(29.8)$ & $<0.001$ \\
\hline Abdominal wall abscess & $11(5.1)$ & $96(3.6)$ & 0.249 & $7(7.3)$ & $114(13.9)$ & 0.072 \\
\hline \multicolumn{7}{|l|}{ Cancer } \\
\hline Colorectal cancer & $10(4.7)$ & $11(0.4)$ & $<0.001$ & $3(3.1)$ & $5(0.6)$ & 0.042 \\
\hline Liver cancer & $9(4.2)$ & $5(0.2)$ & $<0.001$ & $2(2.1)$ & $0(0.0)$ & 0.011 \\
\hline \multicolumn{7}{|l|}{ Hospitalization } \\
\hline Pneumonia & $96(44.9)$ & $114(4.3)$ & $<0.001$ & $36(37.5)$ & $56(6.8)$ & $<0.001$ \\
\hline Urinary tract infection & $69(32.2)$ & $174(6.5)$ & $<0.001$ & $25(26.0)$ & $86(10.5)$ & $<0.001$ \\
\hline Sepsis & $122(57.0)$ & $171(6.4)$ & $<0.001$ & $57(59.4)$ & $112(13.6)$ & $<0.001$ \\
\hline
\end{tabular}




\section{Univariate analysis of risk factors for mortality}

Of the 310 patients (8.2\%) who died during follow-up, 96 had CD and 214 had UC (Table 2). Women had excess mortality in $\mathrm{CD}$ when the survival and mortality groups were compared $(\mathrm{p}=0.038)$. Because $61.7 \% \mathrm{UC}$ and $52.1 \%$ CD patients died older than 60 years (Table 2), age was deemed to be a significant factor affecting mortality $(\mathrm{p}<0.001$ and $\mathrm{p}<0.001)$. The mortality group tended to have received colostomy, exploratory laparotomy, and ileostomy. The rates of comorbidities such as hypertension and diabetes; and infections such as sepsis, pneumonia, and urinary tract infection occurred more frequently in the mortality group. In EIM, cholangitis in UC and deep venous thrombosis in $C D$ were the risk factors of mortality $(p=0.003$ and $p=0.019)$. Deep vein thrombosis and pulmonary embolism (PE) in UC were higher in the mortality group but didn't reach statistical difference. Malignancies such as colorectal cancer, liver cancer and lymphoma were related to the IBD mortality with statistical difference, especially in UC patients. Due to the small cases of lymphoma and pulmonary embolism, the detail was not presented in the Table 2. Surprisingly, fistula as a disease-related complication seemed to occur more frequently in the survival group of CD $(\mathrm{p}<0.001)$. The mortality group more frequently experienced malignancy.

\section{Multivariate analysis of risk factors for mortality}

In the multivariate analysis, pulmonary embolism became a risk factor of mortality in UC. After adjusting the significant univariate factors, the multivariable logistic regression model indicated that mortality in IBD was associated with age, lymphoma, pneumonia and sepsis (Table 3). Among these covariates, the hazard ratio (HR) of mortality in CD increased significantly with lymphoma (HR: 12.26; 95\% CI 2.85-52.63), followed by age groups $\geq 60$ years (HR: 11.93 ; 95\% CI 6.25-22.79) and sepsis (HR: 5.36; 95\% CI 3.41-8.41). In UC patients, the mortality increased significantly with age groups $\geq 60$ years (HR: 8.93; 95\% CI 5.50-14.52), followed by sepsis (HR: 5.40; 95\% CI 3.86-7.56) and pulmonary embolism (HR: 4.21; 95\% CI 1.01-17.57). The operation of colostomy, ileostomy and exploratory laparotomy was still the significant risk factor of mortality in $\mathrm{CD}$, while liver cancer was related to mortality in UC. There was no significant difference in the risk factors of cholangitis, deep venous thrombosis, comorbidity and colorectal cancer.

\section{Mortality rate between different time periods and groups} $\mathrm{CD}$ and UC death rates decreased with time on categorizing mortality into 3 time periods (2001-2005, 20062010, and 2011-2015; Table 4). The mortality rate of CD decreased from $21.2 / 1000$ person-years to $19.9 / 1000$ person-years during 2001-2005 and 2011-2015 $(\mathrm{p}=0.002)$. The mortality rate of UC was $11.6 / 1000$ persons-years during 2001-2005 and 8.5/1000 persons-years during 2011-2015 $(\mathrm{p}=0.020)$. The mortality rate during 2006-2010, prior to the introduction of the training/ online resources in 2010, appeared to decrease slightly in $\mathrm{UC}$ and CD, but the difference in the SMR was not statistically significant between the periods 2001-2005 and 2006-2010. The survival curve of CD and UC patients during this study period is shown in Fig. 1. The 5-, 10-, and 13-year survival rates of $\mathrm{CD}$ patients after registration were $90 \%, 85 \%$, and $80 \%$, respectively, whereas those of UC patients were $95 \%, 91 \%$, and $87 \%$, respectively. The survival rate was significantly higher in the UC group than in the CD group from 2001 to 2015 ( $\mathrm{p}<0.001$ ).

In the age- and gender-stratified specific mortality analysis (Fig. 2), gender did not affect the mortality rate, although men had a higher mortality rate in the UC group (1.19\% vs. $0.92 \%)$ and women had a higher mortality rate in the CD group (1.70\% vs. $2.70 \%)$. When stratified for age, the mortality rates of both UC and $C D$ groups increased with age, with $\geq 60$-year-old CD patients having the highest mortality rate of $10.74 \%$.

\section{SMRs of IBD patients}

The SMRs for all-cause mortality in CD and UC patients during 2001-2015 were 3.72 (95\% CI 3.02-4.55) and 1.44 (95\% CI 1.26-1.65), respectively (Fig. 3). When stratified for different time periods, the SMRs of CD and UC decreased from 5.46 to 2.80 and from 1.88 to 1.36 , respectively, during 2001-2005 and 2011-2015.

\section{Discussion}

Our nationwide cohort study demonstrated a significant decrease in CD and UC mortality rates in Taiwan during 2001 to 2015 . The mortality rate was however higher in $C D$ patients. The $C D$ group had higher infection and surgery rates, whereas the UC group had more comorbidities. Older age, sepsis and pneumonia were the risk factors for mortality in the multivariate analysis. Surgeries were the significant risk factors in CD, while liver cancer was a risk factor in UC. For decreasing the mortality rates associated with IBD, it is vital to recognize and treat the early clinical warning signs of the disease. Our study will assist clinicians in understanding better the risk factors of mortality in IBD patients.

The disease severity of IBD in Asia seems to be equal to or greater than that in the West [9]. Our study reported a higher mortality rate in $C D$ patients, in accordance with findings from previous studies $[10,11]$. With the increase in IBD incidence over the years in Taiwan, physician awareness of the disease has increased, especially through continuous medical education programs for 
Table 3 Multivariable hazard ratios of mortality for IBD patients registered in the Catastrophic Illness Registry, Taiwan, 2001-2015

\begin{tabular}{|c|c|c|c|c|c|c|c|c|}
\hline & \multicolumn{4}{|l|}{ UC } & \multicolumn{4}{|l|}{$\mathrm{CD}$} \\
\hline & $\mathrm{cHR}$ & $95 \% \mathrm{Cl}$ & $\mathrm{aHR}^{\mathrm{a}}$ & $95 \% \mathrm{Cl}$ & $\mathrm{cHR}$ & $95 \% \mathrm{Cl}$ & $a H R^{b}$ & $95 \% \mathrm{Cl}$ \\
\hline \multicolumn{9}{|l|}{ Gender } \\
\hline Female & 1.00 & (Ref.) & & & 1.00 & (Ref.) & 1.00 & (Ref.) \\
\hline Male & 1.29 & $(0.97-1.71)$ & & & 0.65 & $(0.43-0.97)$ & 1.04 & $(0.65-1.66)$ \\
\hline \multicolumn{9}{|l|}{ IBD registered age } \\
\hline$\leq 39$ & 1.00 & (Ref.) & 1.00 & (Ref.) & 1.00 & (Ref.) & 1.00 & (Ref.) \\
\hline $40-59$ & 2.23 & $(1.39-3.59)$ & 2.21 & $(1.37-3.59)$ & 2.91 & $(1.63-5.22)$ & 3.11 & $(1.69-5.72)$ \\
\hline$\geq 60$ & 14.16 & $(9.16-21.88)$ & 8.93 & $(5.50-14.52)$ & 13.95 & $(8.28-23.50)$ & 11.93 & $(6.25-22.79)$ \\
\hline \multicolumn{9}{|l|}{ Operation } \\
\hline Colostomy & 3.67 & $(2.51-5.37)$ & 1.28 & $(0.83-1.95)$ & 3.66 & $(2.26-5.95)$ & 2.27 & $(1.33-3.87)$ \\
\hline Exploratory laparotomy & 5.04 & $(1.87-13.59)$ & 2.41 & $(0.84-6.88)$ & 3.57 & $(1.79-7.10)$ & 2.27 & $(1.04-4.98)$ \\
\hline Ileostomy & 2.69 & $(1.64-4.42)$ & 1.34 & $(0.79-2.27)$ & 3.13 & $(1.51-6.45)$ & 2.26 & $(1.04-4.90)$ \\
\hline \multicolumn{9}{|l|}{ Comorbidity } \\
\hline Hypertension & 2.35 & $(1.80-3.08)$ & 0.69 & $(0.50-0.95)$ & 2.96 & $(1.96-4.47)$ & 0.68 & $(0.39-1.19)$ \\
\hline Diabetes & 2.17 & $(1.57-2.99)$ & 0.76 & $(0.53-1.09)$ & 2.33 & $(1.41-3.85)$ & 0.67 & $(0.35-1.28)$ \\
\hline Hyperlipidemia & 0.84 & $(0.60-1.18)$ & & & 1.66 & $(1.01-2.71)$ & 0.76 & $(0.41-1.40)$ \\
\hline COPD & 2.52 & $(1.79-3.55)$ & 0.82 & $(0.56-1.18)$ & 1.70 & $(0.88-3.28)$ & & \\
\hline \multicolumn{9}{|l|}{ EIM } \\
\hline Cholangitis & 3.81 & $(1.79-8.09)$ & 2.14 & $(0.95-4.81)$ & 2.35 & $(0.86-6.40)$ & & \\
\hline Deep vein thrombosis & 1.99 & $(0.82-4.83)$ & & & 3.14 & $(1.28-7.74)$ & 1.14 & $(0.44-2.98)$ \\
\hline Pulmonary embolism & 8.76 & $(2.17-35.43)$ & 4.21 & $(1.01-17.57)$ & 4.75 & $(0.66-34.24)$ & & \\
\hline \multicolumn{9}{|l|}{ Complication } \\
\hline Fistula & 0.91 & $(0.60-1.37)$ & & & 0.38 & $(0.21-0.68)$ & 0.60 & $(0.32-1.10)$ \\
\hline \multicolumn{9}{|l|}{ Cancer } \\
\hline Colorectal cancer & 6.61 & $(3.50-12.49)$ & 1.84 & $(0.94-3.61)$ & 3.46 & $(1.09-10.92)$ & 1.04 & $(0.27-3.96)$ \\
\hline Liver cancer & 8.59 & $(4.40-16.75)$ & 2.16 & $(1.05-4.42)$ & 14.96 & $(3.67-60.95)$ & 1.80 & $(0.36-9.07)$ \\
\hline Lymphoma & 9.25 & $(3.81-22.48)$ & 3.65 & $(1.45-9.19)$ & 7.38 & $(1.81-30.03)$ & 12.26 & $(2.85-52.63)$ \\
\hline \multicolumn{9}{|l|}{ Hospitalization } \\
\hline Pneumonia & 11.23 & $(8.57-14.70)$ & 2.88 & $(2.08-3.99)$ & 5.27 & $(3.48-7.98)$ & 1.79 & $(1.13-2.85)$ \\
\hline Urinary tract infection & 5.18 & $(3.89-6.91)$ & 0.87 & $(0.62-1.22)$ & 2.52 & $(1.60-3.97)$ & 0.78 & $(0.44-1.38)$ \\
\hline Spesis & 13.09 & $(9.98-17.16)$ & 5.40 & $(3.86-7.56)$ & 6.53 & $(4.34-9.81)$ & 5.36 & $(3.41-8.41)$ \\
\hline
\end{tabular}

CHR crude hazard ratio, aHR adjusted hazard ratio, $\mathrm{Cl}$ confidence interval

a Adjusted risk factor: IBD registered age, Colostomy, Exploratory laparotomy, lleostomy, Hypertension, Diabetes, COPD, Cholangitis, Pulmonary embolism, Colorectal cancer, Liver cancer, lymphoma, Pneumonia, Urinary tract infection, Sepsis

b Adjusted risk factor: Gender, IBD registered age, Colostomy, Exploratory laparotomy, lleostomy, Hypertension, Diabetes, Hyperlipidemia, Deep vein thrombosis, Fistula, Colorectal cancer, Liver cancer, lymphoma, Pneumonia, Urinary tract infection, Sepsis

Table 4 Mortality in IBD patients registered in Catastrophic Illness Registry between 2001 and 2015, Taiwan

\begin{tabular}{|c|c|c|c|c|c|c|c|c|c|c|}
\hline \multirow[t]{2}{*}{ Dx year } & \multicolumn{5}{|c|}{ Crohn's disease } & \multicolumn{5}{|c|}{ Ulcerative colitis } \\
\hline & $D x(n)$ & Death $(n)$ & Person-year & $\begin{array}{l}\text { Mortality } \\
\text { rate } \\
\text { (per } 1000 \\
\text { person-year) }\end{array}$ & $p$ value & $\mathrm{Dx}(n)$ & Death $(n)$ & Person-year & $\begin{array}{l}\text { Mortality } \\
\text { rate } \\
\text { (per } 1000 \\
\text { person-year) }\end{array}$ & $p$ value \\
\hline $2001-2005$ & 205 & 45 & 2125 & 21.2 & $0.002^{\mathrm{a}}$ & 886 & 117 & 10,066 & 11.6 & $0.020^{a}$ \\
\hline $2006-2010$ & 258 & 32 & 1714 & 18.7 & & 1077 & 79 & 7572 & 10.4 & \\
\hline $2011-2015$ & 456 & 19 & 955 & 19.9 & & 924 & 18 & 2110 & 8.5 & \\
\hline
\end{tabular}

a Comparison disease year of 2001-2005 and 2011-2015 


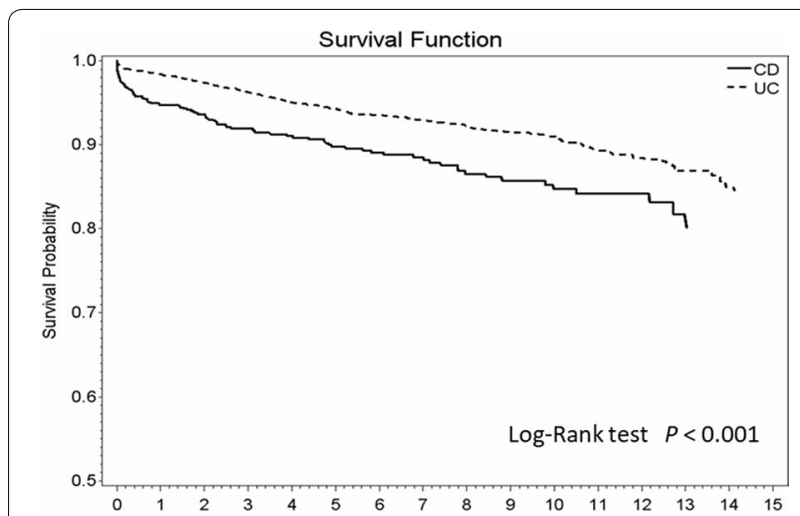

Fig. 1 Survival rate of patients registered in the Catastrophic Illness Registry with IBD, Taiwan, 2001-2015

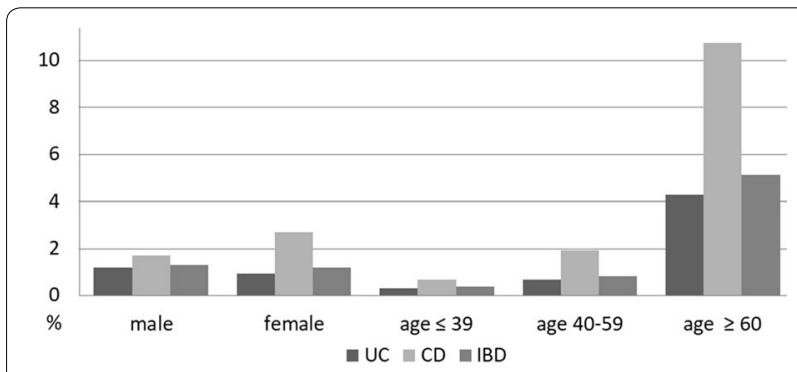

Fig. 2 Age- and gender-stratified specific mortality rate of patients registered in the Catastrophic IIIness Registry with IBD, Taiwan, 2001-2015

IBD since 2009. A previous study reported an increasing trend in the use of immunosuppressant agents for treating UC over the years in Taiwan: 0\% (1998) to 7\% (2008) [12]. A population-based study revealed that immunosuppressant therapy could significantly improve IBD survival rates [13]. Biologics have been demonstrated to aid mucosal healing and decrease the incidence of IBD-related complications following surgery [14]. Adalimumab was the first biologic to be reimbursed by the NHI since 2011 for treating CD, followed by more biologics for the treatment of UC and CD since 2016 [15]. Because of budget limitations, the NHI allows the use of biologics only for a limited period; however, in case of clinical relapse, the patient can apply again [15]. A recent study from Taiwan showed that a high accumulated dose of anti-TNF- $\alpha$ agents and corticosteroid is associated with increased risk of operation [16], which may be because of the severe disease activity and late use of biologics.

A previous study showed that infection-associated mortality was higher in patients with CD than in those with UC [10]. Sepsis and pneumonia were the most common causes of infection-related mortality and abdominal abscesses did not seem to increase the mortality rate [17]; as observed in our study. It was well recognized the incidence of thromboembolic event (VTE) in IBD patients was lower in Asia than in Western countries [18]. Routine thromboprophylaxis was not a standard practice in Asia, while our study showed pulmonary embolism (PE) played an important risk factor of mortality for UC. Therefore, we suggested to closely monitor the possibility of VTE in the admitted IBD patients. In selective condition, for example, when with more risk factors of PE (surgery, malignancy, hormone change- for example, pregnancy or hormone replacement, thrombophilia, and immobilization) [19], prophylaxis might be indicated. In this study, a higher rate of comorbidity in the UC group may be attributed to the higher mean age of UC patients than that of CD patients. A population-based Swiss study revealed a high prevalence of concomitant chronic diseases in IBD patients compared to non-IBD patients;
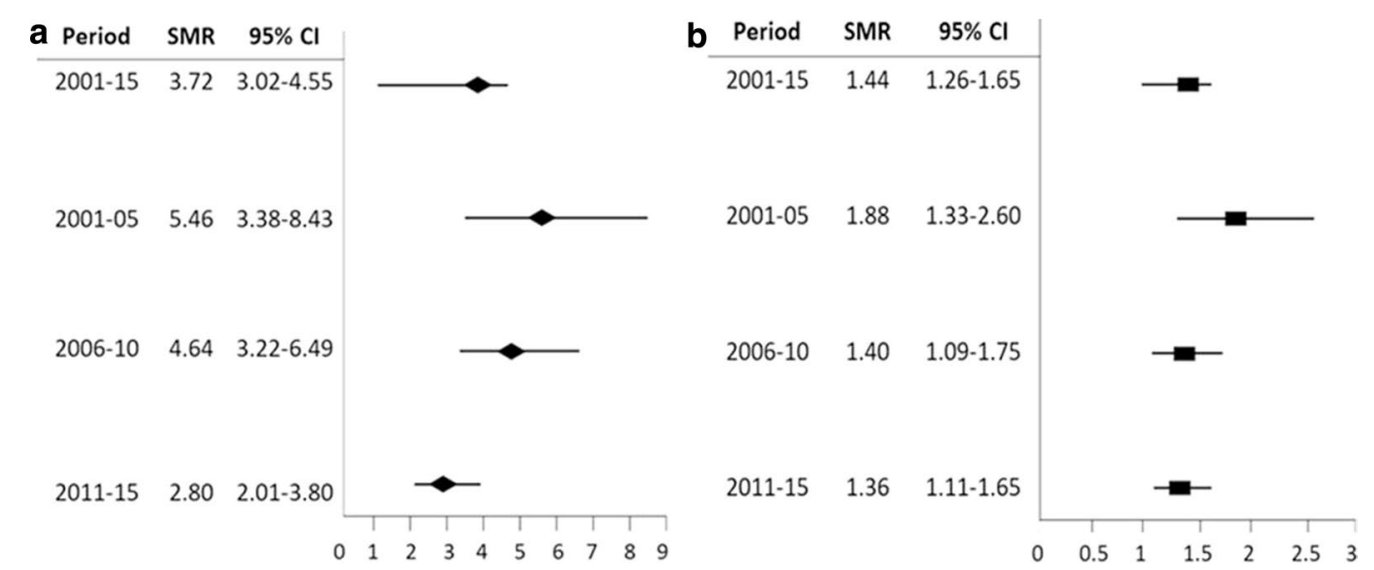

Fig. 3 Standard mortality ratio of $\mathbf{a}$ Crohn's disease and $\mathbf{b}$ ulcerative colitis in different time periods 
$78 \%$ of IBD patients had at least one comorbidity, with a median of three comorbidities [20].

In our study, ostomy or exploratory laparotomy was a risk factor for mortality in CD patients. This result may reflect the fact that this surgery was performed in an emergency or for refractory IBD. Ostomy construction is an effective treatment modality for refractory large bowel $\mathrm{CD}$ or perianal CD [21]. A systematic review reported that emergent surgery for IBD is associated with higher mortality rates [22]. Postoperative mortality decreased significantly over time for CD patients, but not for UC patients [22, 23]. Optimization of medical treatment, especially perioperative care, is necessary for decreasing ostomy-related mortality.

Fistula is a severe complication of $\mathrm{CD}$, and it is associated with increased morbidity and impairment in healthrelated quality of life [24]. In this study, it appeared that fistula was not a factor of mortality. A literature-based analysis showed that anal fistulas were the most common type of fistula [25]. Simple anal fistulas are associated with a better prognosis and are less likely to require radical surgical procedures than complex fistulas [26]. Perianal disease is more commonly detected in East Asian countries than in Western countries [27]. Since patients with perianal disease might seek and adhere to treatment, this might explain why the presence of fistula did not cause mortality in this study.

Long-standing IBD has an increased risk of developing colorectal cancer $(\mathrm{CRC})$ and $\mathrm{CRC}$ is associated with increased mortality $[28,29]$. Other cancers, such as lung cancer, biliary tract tumor, and lymphoma, are also related to the mortality on IBD [11, 28, 29]. Colon cancer, lung cancer, and liver tumor are reported to be the top five common cancers in Taiwan, whereas lymphoma shows an increasing trend of incidence [30]. In this study, we found that liver cancer plays a central role in UC mortality, while CRC was not related to mortality in the multivariate analysis. We searched for liver cancer by using the code 155, which included hepatocellular carcinoma and cholangiocarcinoma. Primary sclerosing cholangitis in IBD patients was a well-known risk factor of cholangiocarcinoma, especially in those with UC. Higher cholangitis rate was also observed in mortality group in UC patients. It is reasonable for liver cancer presented with a high hazard ratio of mortality in UC patients. We also observed CD patients had higher hazard ratios of surgery than $U C$ patients, which suggested that $C D$ patients had more severe disease activity and were more likely to receive immunosuppressants and anti-TNF agents that increased their risk of lymphoma. Due to the reimbursement criteria, more $\mathrm{CD}$ patients received thiopurine and anti-TNF agents than UC patients in Taiwan during this study period [16]. We did not identify any melanoma or non-melanoma skin cancer in our IBD patients during follow-up because of the rarity of malignant melanoma in Asia. Regarding extraintestinal cancers, surveillance programs for malignancy are needed to closely monitor IBD patients.

One review article that included studies conducted during 1980-2010 demonstrated an SMR of approximately 1.5-fold (range, $0.7-2.2$ ) for CD patients, whereas the SMR for UC patients was similar to that of the general population (range, 0.7-1.7) [6]. IBD mortality and treatment outcomes might have changed with the development of biologics since 1998. In Taiwan, the SMRs for CD and UC were 3.72 and 1.44, respectively, higher than that reported in Korea and other Western countries during the same period [28, 29, 31, 32]. With the introduction of training/online resources in 2010 and the introduction of biologics reimbursement in Taiwan in 2011, the SMRs of CD and UC gradually decreased to 2.80 and 1.36, respectively. Realizing the risk factors of mortality and proper management of complications are important to lower IBD-related mortality, especially in CD.

The strength of this study was the availability of a large, nationwide cohort of individuals with IBD from a country that provides access to healthcare and registration for all its citizens. However, there are limitations in our study. First, elderly people tend to have more comorbidities; therefore, aging itself as the exact cause of death may oversimplify the reality. The exact cause of death is difficult to determine and complex; therefore, our study chose the contributing risk factors of death. Second, only IBD patients who had a certificate for catastrophic illnesses were registered, and those with mild illnesses were excluded. This may have led to an overestimated mortality rate and delayed age of disease onset (registered). Third, detailed clinical data such as phenotype, laboratory results, disease duration, and smoking and family histories were not available for the included patients. Fourth, IBD follow-up periods for biologics use, comorbidities, and malignancies were short, which impeded the analysis of natural course patterns. Nevertheless, our results could be useful in countries with an increasing incidence and prevalence of IBD where physicians are beginning to gain insights into IBD treatment. Education on IBD, as in the pre-biologic era, can help decrease disease-related mortality.

\section{Conclusion}

This is the first Taiwanese nationwide database study focusing on the risk factors of IBD mortality. Although $C D$ patients had higher mortality, the mortality rates of both CD and UC were significantly decreased from 2001 
to 2015. Awareness of the disease in elderly individuals, infection control, and improvement in perioperative care could help decrease IBD-related mortality.

\begin{abstract}
Abbreviations
Anti-TNF-a: anti-tumor necrosis factor alpha; CD: crohn's disease; Cl: confidence interval; COPD: chronic obstructive pulmonary disease; CRC: colorectal cancer; EIMs: extraintestinal manifestations; HR: hazard ratio; HWDC: Health and Welfare Data Science Center; IBD: inflammatory bowel disease; ICD: international classification of diseases; MOHW: Ministry of Health and Welfare; NHI: National Health Insurance; PE: pulmonary embolism; SMRs: standardized mortality ratios; UC: ulcerative colitis; VTE: venous thromboembolic event.
\end{abstract}

\section{Acknowledgements}

We express our gratitude to all the individuals associated with the integrated database of the Department of Medical Research of the National Taiwan University Hospital and the National Taiwan University Health Data Research Center for their technical assistance.

\section{Authors' contributions}

Conceptualization, JMW and SCW; data curation, WCL; formal analysis, MTW, CCT, YLL, and HYW; methodology, YTC and YTW; resources, CCT and YLL; supervision, JMW and HYW; writing (original draft), WCL; writing (review and editing), SCW. All authors read and approved the final manuscript.

\section{Funding}

This work was supported by the National Taiwan University Hospital Research Program Ms160 (to JMW), 107-A139 (to SCW), the Liver Disease Prevention and Treatment Research Foundation, Taiwan (to MTW and SCW).

\section{Availability of data and materials}

The datasets generated during and/or analysed during the current study are available in the Health and Welfare Data Science Center, Ministry of Health and Welfare repository, Taiwan. (https://dep.mohw.gov.tw/DOS/Ip-2506-113.html).

\section{Ethics approval and consent to participate}

Each participant included in this study signed a written informed consent form before taking the survey. Ethics approval for the data collection was obtained from the Institutional Review Board of the National Taiwan University Hospital (IRB Number 201507018W).

\section{Consent for publication}

Not applicable.

\section{Competing interests}

The authors declare that they have no competing interests.

\section{Author details}

1 Division of Gastroenterology, Department of Internal Medicine, MacKay Memorial Hospital, Taipei City, Taiwan. ${ }^{2}$ MacKay Junior College of Medicine, Nursing and Management, Taipei, Taiwan. ${ }^{3}$ MacKay Medical College, Taipei, Taiwan. ${ }^{4}$ Department of Internal Medicine, National Taiwan University Hospital and College of Medicine, Taipei City, Taiwan. ${ }^{5}$ School of Medicine, National Taiwan University, Taipei City, Taiwan. ${ }^{6}$ Health Data Research Center, National Taiwan University, Taipei City, Taiwan. ${ }^{7}$ Department of Internal Medicine, West Garden Hospital, Taipei City, Taiwan. ${ }^{8}$ Inflammatory Bowel Disease Clinical and Study Integrated Center, National Taiwan University Hospital, Taipei City, Taiwan.

Received: 10 September 2019 Accepted: 2 December 2019

Published online: 12 December 2019

\section{References}

1. Mowat C, Cole A, Windsor A, Ahmad T, Arnott I, Driscoll R, et al. Guidelines for the management of inflammatory bowel disease in adults. Gut. 2011:60(5):571-607.
2. Sonnenberg A. Time trends of mortality from Crohn's disease and ulcerative colitis. Int J Epidemiol. 2007;36(4):890-9.

3. Kassam Z, Belga S, Roifman I, Hirota S, Jijon H, Kaplan GG, et al. Inflammatory bowel disease cause-specific mortality: a primer for clinicians. Inflamm Bowel Dis. 2014;20(12):2483-92.

4. Jess T, Gamborg M, Munkholm P, Sørensen TI. Overall and cause-specific mortality in ulcerative colitis: meta-analysis of population-based inception cohort studies. Am J Gastroenterol. 2007;102(3):609-17.

5. Duricova D, Pedersen N, Elkjaer M, Gamborg M, Munkholm P, Jess T. Overall and cause-specific mortality in Crohn's disease: a meta-analysis of population-based studies. Inflamm Bowel Dis. 2010;16(2):347-53.

6. Selinger CP, Leong RW. Mortality from inflammatory bowel diseases. Inflamm Bowel Dis. 2012;18(8):1566-72.

7. Wei SC, Lin MH, Tung CC, Weng MT, Kuo JS, Shieh MJ, et al. A nationwide population-based study of the inflammatory bowel diseases between 1998 and 2008 in Taiwan. BMC Gastroenterol. 2013:13:166.

8. Health and Welfare Data Science Center, Ministry of Health and Welfare, Taiwan. https://dep.mohw.gov.tw/DOS/lp-2506-113.html. Accessed 20 Oct 2017

9. Ng SC, Tang W, Ching JY, Wong M, Chow CM, Hui AJ, et al. Incidence and phenotype of inflammatory bowel disease based on results from the Asia-pacific Crohn's and colitis epidemiology study. Gastroenterology. 2013;145(1):158-65.

10. Jess T, Frisch M, Simonsen J. Trends in overall and cause-specific mortality among patients with inflammatory bowel disease from 1982 to 2010. Clin Gastroenterol Hepatol. 2013;11(1):43-8.

11. Kim HJ, Hann HJ, Hong SN, Kim KH, Ahn IM, Song JY, et al. Incidence and natural course of inflammatory bowel disease in Korea, 2006-2012: a nationwide population-based study. Inflamm Bowel Dis. 2015;21(3):623-30.

12. Chen CY, Lee KT, Charles Tzu-Chi L, Lai WT, Huang YB. Epidemiology and disease burden of ulcerative colitis in Taiwan: a nationwide populationbased study. Value Health Reg Issues. 2013;2(1):127-34.

13. Romberg-Camps M, Kuiper E, Schouten L, Kester A, Hesselink-van de Kruijs M, Limonard C. Mortality in inflammatory bowel disease in the Netherlands 1991-2002: Results of a population-based study: The IBD South-Limburg cohort. Inflamm Bowel Dis. 2010;16(8):1397-410.

14. de Buck van Overstraeten AD, Wolthuis A, D'Hoore A. Surgery for Crohn's disease in the era of biologicals: A reduced need or delayed verdict? World J Gastroenterol. 2012;18(29):3828.

15. Su HJ, Chiu YT, Chiu CT, Lin YC, Wang CY, Hsieh JY, et al. Inflammatory bowel disease and its treatment in 2018: global and Taiwanese status updates. J Formos Med Assoc. 2019;118(7):1083-92.

16. Weng MT, Tung CC, Chang YT, Leong YL, Wang YT, Wong JM, et al. Trends of medication usage and associated outcomes for Taiwanese patients with inflammatory bowel disease from 2001 to 2015. J Clin Med. 2018;7(11):394

17. Ananthakrishnan AN, McGinley EL. Infection-related hospitalizations are associated with increased mortality in patients with inflammatory bowel diseases. J Crohns Colitis. 2013;7(2):107-12.

18. Weng MT, Tung CC, Wong JM, Wei SC. Should Asian inflammatory bowel disease patients need routine thromboprophylaxis? Intest Res. 2018:16(2):312-4

19. Doherty S. Pulmonary embolism an update. Aust Fam Physician. 2017:46(11):816-20.

20. Bähler C, Schoepfer AM, Vavricka SR, Brüngger B, Reich O. Chronic comorbidities associated with inflammatory bowel disease: prevalence and impact on healthcare costs in Switzerland. Eur J Gastroenterol Hepatol. 2017;29(8):916-25.

21. Wang X, Shen B. Management of Crohn's disease and complications in patients with ostomies. Inflamm Bowel Dis. 2018;24(6):1167-84.

22. Singh S, Al-Darmaki A, Frolkis AD, Seow CH, Leung Y, Novak KL, Ghosh S, et al. Postoperative mortality among patients with inflammatory bowel diseases: a systematic review and meta-analysis of population-based studies. Gastroenterology. 2015;149(4):928-37.

23. Lin CC, Wei SC, Lin BR, Tsai WS, Chen JS, Hsu TC, et al. A retrospective analysis of 20-year data of the surgical management of ulcerative colitis patients in Taiwan: a study of Taiwan Society of Inflammatory Bowel Disease. Intest Res. 2016;14(3):248-57. 
24. Mahadev S, Young JM, Selby W, Solomon MJ. Quality of life in perianal Crohn's disease: what do patients consider important? Dis Colon Rectum. 2011;54(5):579-85.

25. Schwartz DA, Tagarro I, Carmen Díez M, Sandborn WJ. Prevalence of fistulizing Crohn's disease in the United States: estimate from a systematic literature review attempt and population-based database analysis. Inflamm Bowel Dis. 2019;25(11):1773-9.

26. Bell SJ, Williams AB, Wiesel P, Wilkinson K, Cohen RC, Kamm MA. The clinical course of fistulating Crohn's disease. Aliment Pharmacol Ther. 2003;17(9):1145-51.

27. Ng WK, Wong SH, Ng SC. Changing epidemiological trends of inflammatory bowel disease in Asia. Intest Res. 2016;14(2):111-9.

28. Jess T, Loftus EV Jr, Harmsen WS, Zinsmeister AR, Tremaine WJ, Melton L 3rd, et al. Survival and cause specific mortality in patients with inflammatory bowel disease: a long term outcome study in Olmsted county, Minnesota, 1940-2004. Gut. 2006;55(9):1248-54.

29. Jussila A, Virta LJ, Pukkala E, Färkkilä MA. Mortality and causes of death in patients with inflammatory bowel disease: a nationwide register study in Finland. J Crohns Colitis. 2014;8(9):1088-96.
30. Chiang CJ, Lo WC, Yang YW, You SL, Chen CJ, Lai MS. Incidence and survival of adult cancer patients in Taiwan, 2002-2012. J Formos Med Assoc. 2016;115(12):1076-88.

31. Lee HS, Choe J, Kim SO, Lee SH, Lee HJ, Seo H, et al. Overall and causespecific mortality in Korean patients with inflammatory bowel disease: a hospital-based cohort study. J Gastroenterol Hepatol. 2017;32(4):782-8.

32. Bitton A, Vutcovici M, Sewitch M, Suissa S, Brassard P. Mortality trends in Crohn's disease and ulcerative colitis: a population-based study in Québec Canada. Inflamm Bowel Dis. 2016;22(2):416-23.

\section{Publisher's Note}

Springer Nature remains neutral with regard to jurisdictional claims in published maps and institutional affiliations.
Ready to submit your research? Choose BMC and benefit from:

- fast, convenient online submission

- thorough peer review by experienced researchers in your field

- rapid publication on acceptance

- support for research data, including large and complex data types

- gold Open Access which fosters wider collaboration and increased citations

- maximum visibility for your research: over $100 \mathrm{M}$ website views per year

At BMC, research is always in progress.

Learn more biomedcentral.com/submissions 